\title{
PENSAMENTO FILOSÓFICO AFRICANO, AFRO-BRASILEIRO E O ENSINO DE HISTÓRIA E CULTURA AFRICANA E AFRO-BRASILEIRA: OUTRO OLHAR (FORMAÇÃO E ENCANTAMENTO)
}

\author{
Adilbênia Machado ${ }^{1}$
}

\section{Resumo}

Esse artigo tem o intuito de pensar o ensino de história e cultura africana e afrobrasileiro desde a perspectiva da filosofia africana contemporânea. Tem o encantamento como delineador para a formação em torno das relações étnicoraciais, refletindo uma educação inclusiva e que valoriza a diversidade. Traz reflexões e perspectivas para um currículo outro por meio do personagem Ananse, onde o conhecimento só faz sentido compartilhado.

Palavras-chave: filosofia africana, ensino de história e cultura africana e afrobrasileira, formação, currículo, encantamento.

\section{Resumen}

Este artículo pretende pensar la enseñanza de la historia de África y de la cultura africana y africano-brasileña desde la perspectiva de la filosofía africana contemporánea. Tiene el encanto como delineador para la formación en torno a las relaciones étnico-raciales, lo que refleja una educación inclusiva y que valora la diversidad. Trae reflexiones y perspectivas para un currículum a través del personaje Ananse, donde el conocimiento sólo tiene sentido compartido.

Palabras clave: filosofía africana; la enseñanza de la historia y la cultura africana y africano-brasileño; formación; currículum; encantamiento

\section{Breve Introdução: apresentando o personagem.}

Mais de uma década passou-se e continuamos a falar sobre a Lei 10.639 / 2003, a primeira lei sancionada pelo primeiro governo de Luís Inácio Lula da Silva, como se fosse recém-nascida, assim, poderíamos estar comemorando a sua década, infelizmente não é essa a realidade! Entretanto, não devemos cair em lamentações, mas refletirmos e agirmos para sua implementação em todos os

\footnotetext{
${ }^{1}$ Doutoranda em Educação (UFC) Mestra em Educação (UFBA); Bacharel e Licenciada em Filosofia (UECE). Faz parte dos grupos de pesquisa GRIÔ: culturas populares, ancestralidade africana e educação, Formacce em Aberto: grupo de pesquisa em currículo e formação, ambos da UFBA. Membro do NACE (Núcleo das Africanidades Cearenses). E-mail: adilmachado@yahoo.com.br.
}

MACHADO, Adilbênia. Pensamento filosófico africano, afro-brasileiro e o ensino de história e cultura africana $e$ afro-brasileira: outro olhar (formação $e$ encantamento). Revista Sul-Americana de Filosofia e Educação. Número 24: maioout/2015, p. 3-23. 
espaços escolares, desse modo, nos encontramos num momento próprio às ações! A promulgação da lei mostrou-se um avanço no que diz respeito a uma educação antirracista, a força do movimento negro e de intelectuais envolvidos com o tema, ao mesmo tempo em que mostra uma significativa fragilidade no que diz respeito à sua implementação, desse modo, no intuito de pensar ações, e refletir outros olhares para a efetivação dessa lei, apresento-lhes o personagem central do texto, que traz em si a cultura africana "adaptada" à cultura afro-brasileira, proporcionando reflexões sobre "outro olhar" para a formação: Ananse!

Ananse, na simbologia Adinkra, é uma teia de aranha que traz em si o significado de "sabedoria, esperteza, criatividade e a complexidade da vida", por gostar de teias de aranha desde a minha infância, comecei a pesquisar sobre essa aranha, que na simbologia citada é Ananse Ntontan. Tal aranha pode ser tanto masculina, como feminina (confesso que ainda não encontrei história da Ananse feminina) e também possui vários nomes, no norte do Togo $^{2}$ com os povos Kabides chama-se de Andjau e é masculino, além de apresentar-se como um herói que pode possuir todas as qualidades e defeitos, alternadamente ${ }^{3}$.

Marina de Mello e Souza no livro "Histórias de Ananse" diz que, segundo a tradição, o povo Ashante (ou Asante), que pertencia a um grupo maior chamado Akan, foram os primeiros a contar as histórias de Ananse. Eles habitavam a região costeira $e$ as florestas tropicais da África Ocidental, na região de Gana, e acabaram tornando-se o grupo mais importante entre os vários povos akans e no final do século XVII tornaram-se parceiros dos europeus no tráfico dos escravizados, que foram para as colônias da América, assim, quando eram vendidos e vinham para a América traziam várias histórias que eram contadas em suas aldeias. Em Gana, Ananse é um personagem muito popular, dos mais velhos para os mais novos as aventuras dessa sapeca aranha que vive como gente, comportando-se como um homem, são transmitidas.

\footnotetext{
${ }^{2}$ O Togo fica entre Gana e a República do Benin. O sistema de símbolos adinkras é um dos saberes da cultura dos povos Akan que ficam no Gana, na Costa do Marfim e no Togo, esses países localizam-se no oeste da África.

${ }^{3}$ Vide: Pinguilly, 2005.

${ }^{4}$ Adwoa Badoe (Ganensa, estudou medicina é Contadora de Histórias Africanas e Professora de Danças Africanas) e Baba Wagué Diakité é do Mali e ilustrador do livro.
} 
Nosso personagem continuamente dá um jeito de sair das enrascadas em que se mete, nem sempre se dá bem, mas suas histórias tem o objetivo de ensinar algo, dizendo o "porquê das coisas", como no nosso conto, "ensinam" maneiras de se comportar e conviver bem com todos, além da importância do respeito aos mais velhos, de não enganar, mentir e agir por inveja, além de ensinar a aceitar as singularidades de cada ser, com suas limitações, suas particularidades, etc.

\subsection{Ananse aprendendo e espalhando conhecimento ${ }^{5}$ :}

Conta uma história africana que certa vez Kwaku Ananse estava sentado a contemplar o sol, pensando nas suas proezas, quando se sentiu extremamente vaidoso por ser tão inteligente. Sorrindo, falou para si mesmo:

- Realmente, sou muito esperto. Não acredito que haja alguém mais inteligente do que eu! Mas, no mesmo instante, veio-lhe uma dúvida e Ananse ficou preocupado:

- É certo que sou inteligente, mas existem tantos povos diferentes...

Eu posso não ser o mais sábio de todos... Pode haver alguém mais sábio do que eu!

Isso o incomodou muito $e$, depois de refletir um pouco, Ananse teve uma ideia:

- Ah, ah, ah, grande Ananse, só você mesmo para ter essa ideia!

Já sei o que vou fazer, já sei! E concluiu satisfeito:

- Vou sair pelo mundo pedindo um pouco de sabedoria a cada pessoa que encontrar pelo caminho. Coloco tudo dentro de uma grande cabaça e então certamente

eu serei o mais sábio de todos!

(...) Não demorou para que a cabaça de Ananse transbordasse de sabedoria.

\footnotetext{
${ }^{5}$ Título original: $\mathrm{O}$ dia em que Ananse espalhou a sabedoria pelo mundo. É importante destacar aqui que esse conto é usado em sua integra na dissertação de mestrado defendida, por mim, em 2014.1 na Faculdade de Educação da Universidade Federal da Bahia. Também reitero que muito deste texto encontra-se na dissertação.
} 
(...) Vou esconder a sabedoria na copa desta árvore e nunca terei de me preocupar com os ladrões que possam querer roubá-la de mim! Ananse foi até a árvore para escalá-la...

Sem perder tempo, começou a escalar a árvore. Entretanto, a grande cabaça, completamente cheia de sabedoria, não permitia que ele subisse.

Tentou e tentou inúmeras vezes, mas nada conseguiu.

Naquele momento, apareceu o filho mais novo de Ananse.

Vendo seu pai naquela luta para atingir a copa da árvore, aproximou-se e perguntou:

- Meu pai, o que faz aí tentando subir nessa árvore?

Ananse respondeu:

- Eu vou tentar escalá-la para guardar na sua copa esta grande cabaça, que está cheia de sabedoria!

E seu filho falou:

- Mas, meu pai, não seria muito mais fácil se você amarrasse a cabaça nas costas,

em vez de amarrá-la na barriga?

Dessa maneira as pernas ficariam livres para escalar a árvore!

Ao ouvir aquilo, Ananse sentou-se e ficou em silêncio por algum tempo...

(...) Ananse desamarrou a cabaça da barriga e novamente a amarrou nas costas, subindo tranquilamente na árvore e resolvendo seu grande problema.

Ao alcançar a copa da árvore, gritou para os ventos:

- Andei e andei por toda parte coletando sabedoria e acreditava ser a pessoa mais sábia de todas! Mas hoje vi que meu filho, que ainda é criança, é mais sábio do que eu. Hoje aprendi uma valiosa lição: que sempre haverá alguém mais sábio que nós e sempre poderemos aprender muito com isso!

Então Ananse levantou a grande cabaça e, virando-a, derramou toda a sabedoria, que, carregada pelos ventos, espalhou-se pelos lugares mais distantes da Terra... (Miranda, 2008). 
Seguindo o conto, o texto aqui apresentado encontra-se emaranhado nas teias de Ananse. Com todo um desejo de conhecer, com uma complexidade própria do ato de conhecer / descobrir / aprender / ensinar... teias que buscam agregar, festejar a vida e o que constitui o próprio existir: o educar / aprender.

$\mathrm{O}$ ato de educar, a educação, visa promover, ao indivíduo, o desenvolvimento ético, moral, cognitivo, físico e emocional, instruir para a vida, desse modo, apresenta-se como um instrumento de transformação onde o seu comprometimento maior é a promoção do bem-viver do homem como um todo, onde seus valores e comportamento no cotidiano seja respeitoso com os diferentes grupos étnicos e sociais. O conhecimento é um acontecimento empírico, fruto das experiências que criam e re-criam o evento do próprio existir. $\mathrm{O}$ conhecimento desejado apresenta-se como fruto das experiências que valorizam as diferentes culturas, re-conhecendo seus valores e grandiosidade, assim como seus autores, pois a história é produto do coletivo da sociedade e seus acontecimentos.

Nosso personagem Ananse com suas vivências / experiências e com as singularidades do caminho percorrido em busca de "todo o conhecimento do mundo", tece aprendizados, constrói epistemologias e aqui ele edifica sua teia propondo uma filosofia entrelaçada nas teias dos ensinamentos que tem a ancestralidade africana como guia e assim o re-conhecimento da nossa origem, a valorização das nossas tradições, das nossas diversidades e singularidades, desejo pela integração e inclusão, ou seja, práxis incorporadas de simbologias, onde o corpo, a emoção e as sensações estão entrelaçadas no ato de conhecer / aprender / ser. Aqui os fios que tecem essas teias são os fios da história e cultura africana $e$ afro-brasileira, desembocando na filosofia africana que é oriunda do encantamento.

A educação africana e afrodescendente desenvolve uma pedagogia em diálogo com a origem, assentada na experiência, implicando no ressignificar o olhar. A ação do ressignificar, dentro do contexto escolhido, aparece como papel do currículo que "como um espaço de significação, está estreitamente vinculado ao processo de formação de identidades sociais" (SILVA, 2010, p. 27). 
Na atualidade é imprescindível construir um currículo que prima pelo encantamento, ou seja, a responsabilidade / cuidado por si e pelo outro, delineados num compromisso ético de promover melhorias para o viver. Tal currículo necessitará ter o contexto como fundamental e fundante para e na "produção" de conhecimento. É imperativo uma educação e um espaço "educativo", que faz a opção pelo respeito e desejo pela diversidade, um currículo pautado no contexto e no indivíduo, promovendo uma educação que se apresenta como um movimento de alteridade, um movimento de encantamento do homem com o aprender/ensinar, pois "a educação aprende com o homem a continuar o trabalho da vida" (BRANDÃO, 2007, p. 13), o trabalho da vida é conhecer e compartilhar conhecimentos / experiências.

O currículo trabalhado na perspectiva de um contador de histórias, como um griot que sai pelo mundo narrando histórias, adaptando-as aos lugares por onde passa, dedicando-se a ensinar por meio dos conhecimentos das comunidades, dos ancestrais, perpetuando movimentos éticos de inclusão, reconhecimento e valorização, oriundo de um grande ensinamento desses ancestrais que nos dizem que "na grande rede de participação que caracteriza o universo estamos todos indelevelmente ligados." (RIBEIRO, 1998, p. 65).

Desse modo, o intento é compartilhar conhecimentos, pois só assim há a possibilidade de valorizar a diversidade, a pluralidade cultural que nos contempla $e$ nos liga. O currículo astuto como Ananse ao aprender com o cotidiano implica-se com esse cotidiano e provoca mudanças significativas na educação, na formação do indivíduo e por consequência na própria sociedade.

Ananse usa sabedoria entrelaçada com esperteza e artimanhas para alcançar seus objetivos e com suas experiências transforma sua vida em contos que objetivam originar ensinamentos, proporcionando encantamento com o existir. Podemos, então, trazer para o nosso currículo, contos africanos e indígenas e assim contar como essas culturas nos formaram e como são fundamentais para nos conhecermos e re-conhecermos nossas origens. Lembrando que todas as culturas devem ser estudas, refletindo num currículo multi e não monocêntrico. 
Dessas pequenas nuances das artimanhas de Ananse compreendemos que a lei 10.639 / 2003 apresenta-se como um instrumento que questiona e coloca em xeque as construções ideológicas de dominação fundadoras da sociedade brasileira, possibilitando rompimentos com o predomínio do paradigma eurocêntrico na educação, porquanto implica numa ampla modificação curricular (que se deseja transformadora) dos cursos de formação dos profissionais da educação ${ }^{6}$. Dessa forma, aponta perspectivas de saída do silenciamento imposto por uma "internalização dos discursos coloniais" (FLOR DO NASCIMENTO; BOTELHO, 2010) que prevalecem em nossa educação.

Assim, a Lei 10.639 apresenta-se como um instrumento que luta contra o racismo e a criminalidade que aflige a população negra, desse modo, a formação para o reconhecimento da nossa ancestralidade africana proporciona consciência política e ética, levando-nos a luta contra o racismo, trabalhando em prol das relações étnico-raciais. Como nos aponta Ronilda Ribeiro (1998, p. 65) :

O contato com a Ética e a Estética africanas necessariamente induzem sentimentos de orgulho de pertença étnica e racial nos afrodescendentes e nos brasileiros em geral. Resgatar a importância da mão e da voz africanas na construção física $e$ simbólica desta terra brasileira é tarefa inadiável, à qual somos chamados hoje, como nunca antes.

É de suma importância salientar que a lei não tem por objetivo "mudar um foco etnocêntrico marcadamente de raiz europeia por um africano, mas de ampliar o foco dos currículos escolares para a diversidade cultural, racial, social e econômica brasileira" (BRASIL, 2004, p. 17). Apresenta-se, então, como uma decisão política de repercussões intensas, tanto nas conjecturas pedagógicas como na formação de professores, assim, faz-se necessário condições excelentes para formação e instrução aos diferentes níveis e modalidades de ensino, em todos os estabelecimentos. É uma lei que resulta, dentre outros, na formação / construção de uma consciência política e histórica da e para a diversidade, que fortalece as

\footnotetext{
${ }^{6} \mathrm{O}$ texto não se destina a falar sobre formação de professores, mas, ao analisar criticamente ações para a implementação da Lei 10.639 percebe-se que é preciso uma formação para que os profissionais da educação possam colocar tal lei em prática.
} 
identidades, as singularidades, além de romper com imagens negativas em relação à população negra, imagens estas que foram construídas durante séculos etc. Bem nos diz Nilma Lino Gomes (2000, p. 149) ao afirmar que:

seria interessante se pudéssemos construir experiências de formação em que os professores pudessem vivenciar, analisar e propor estratégias de intervenção que tenham a valorização da cultura negra $e$ a eliminação de práticas racistas como foco principal. Dessa forma, o entendimento dos conceitos estaria associado às experiências concretas, possibilitando uma mudança de valores. Por isso, o contato com a comunidade negra, com os grupos culturais $e$ religiosos que estão ao nosso redor é importante, pois uma coisa é dizer, de longe, que se respeita o outro, e outra coisa é mostrar esse respeito na convivência humana, é estar cara a cara com os limites que o outro me impõe, é saber relacionar, negociar, resolver conflitos, mudar valores.

O/a negro/a africano/a e sua diversidade cultural alterou não apenas o português existente no Brasil, mas também a estética, a culinária, os costumes, os valores e princípios éticos, assim como a religião, afinal a cultura resulta das experiências humanas, e são infinitas influências africanas que perduram nos transformando na maior população afrodescendente concentrada fora do continente africano ${ }^{7}$. Efetivamente,

seria um engano conhecer o Brasil sem conhecer a história dos afrodescendentes. Seria um engodo compreender o Brasil sem antes conhecer a África. Seria uma lástima procurar entender a realidade social brasileira sem compreender a realidade racial do país. Combater a discriminação racial não é tarefa exclusiva do poder judiciário. É preciso re-pensar a história brasileira a partir do legado africano. Sem isso, perderíamos em profundidade e qualidade o conhecimento sobre nós mesmos. A brasilidade, em muito é tributária da africanidade. (OLIVEIRA, 2006, p. 18).

\footnotetext{
${ }^{7}$ Vide Adilbênia Machado, 2011.
} 
A educação escolar necessita mudar o foco, o modo de ver, sentir e compartilhar conhecimentos, além de sair do silenciamento e reivindicar nossas diversas epistemologias, imprimindo uma ética de valorização de nós mesmos, pois o "debate ético (..) implica a responsabilidade, o mutualismo, a capacidade de reconhecer a incompletude infinita, para daí, trabalharmos (...) com a honestidade que demandam num cenário eleito formativo" (MACEDO, 2010, p. 125), esse cenário é o nosso lugar de origem, de vivência e experiências.

\subsection{Refletindo sobre a Lei 10.639/03 e o Ensino Superior}

Compreendo que a Lei $10.639^{8}$, no que diz respeito ao ensino de História e Cultura Africana e Afro-brasileira, não deve ser direcionada apenas para o Ensino Básico, mas, também e de modo enfático ao Ensino Superior, pois este é o responsável pela formação dos educadores que vão para o ensino básico, e ainda que se indique o Ensino de $\mathrm{HCAA}^{9}$ em componentes curriculares específicos (literatura, arte e história do Brasil) entendo que é um tema transversal a todos componentes curriculares não estando contemplada apenas no currículo de História, Artes e Literatura, mas também na história, na geografia, na ciência (biologia, química), na língua portuguesa, na matemática, na física, na filosofia etc. Ou seja, a instituição superior necessita responsabilizar-se, também, por fazer essa formação, realizando programas de formação continuada, cursos de extensão, cursos de graduação, de pós-graduação, formando profissionais para não apenas disseminar o conhecimento da História e Cultura da África e dos afrodescendentes, mas sensibilizar para uma educação antirracista. Não há como efetivar a lei se não houver capacitação / formação para os professores / educadores, assim como os gestores e demais funcionários de cada escola, pois

ainda encontramos muitos(as) educadores(as) que pensam que discutir sobre relações raciais não é tarefa da educação. É um dever dos militantes políticos, dos sociólogos e antropólogos. Tal argumento demonstra uma total incompreensão sobre a formação histórica e cultural da

\footnotetext{
${ }^{8}$ Em 2009 essa lei fora alterada para a Lei 11.645, acrescentando o ensino da história indígena.

${ }^{9}$ História e Cultura Africana e Afro-brasileira.
} 
sociedade brasileira. E, ainda mais, essa afirmação traz de maneira implícita a ideia de que não é da competência da escola discutir sobre temáticas que fazem parte do nosso complexo processo de formação humana. Demonstra, também, a crença de que a função da escola está reduzida à transmissão dos conteúdos historicamente acumulados, como se estes pudessem ser trabalhados de maneira desvinculada da realidade social brasileira (GOMES, 2000, p. 146).

É necessário pontuar que ainda que a secretaria de educação promova alguns cursos de formação continuada essa ação não é suficiente, assim sendo, o sistema de ensino superior deve agir em parceria com a secretaria de educação. Pois, sabemos que:

Não existem leis no mundo que sejam capazes de erradicar as atitudes preconceituosas existentes nas cabeças das pessoas, atitudes essas provenientes dos sistemas culturais de todas as sociedades humanas. No entanto, cremos que a educação é capaz de oferecer tanto aos jovens como aos adultos a possibilidade de questionar e desconstruir os mitos de superioridade e inferioridade entre grupos humanos que foram introjetados neles pela cultura racista na qual foram socializados. Apesar da complexidade da luta contra o racismo, que consequentemente exige várias frentes de batalhas, não temos dúvida de que a transformação de nossas cabeças de professores é uma tarefa preliminar importantíssima. Essa transformação fará de nós os verdadeiros educadores, capazes de contribuir no processo de construção da democracia brasileira, que não poderá ser plenamente cumprida enquanto perdurar a destruição das individualidades históricas e culturais das populações que formaram a matriz plural do povo e da sociedade brasileira (MUNANGA, 2000, p. 17).

Além da formação de professores / educadores, é fundante repensar e continuar produzindo um material didático que saia do monocentrismo eurocêntrico, repensarmos ainda as práticas escolares, pois as temáticas abordadas na Lei 10.639 / 11.645 fazem parte do cotidiano, assim necessita, também, estar presente nos planejamentos, além de ser trabalhada continuamente por toda a equipe pedagógica de cada escola. Estamos falando de relações étnico-raciais, de 
re-conhecimento do Outro, de respeito à cultura do Outro, de conhecimento de nós mesmos, da diversidade cultural, assim como das singularidades de cada contexto, é uma discussão permanente e transversal, como já fora dito. Pois, segundo o que nos diz Nilma Lino Gomes (2000, p. 145),

é preciso que as práticas pedagógicas sejam orientadas por princípios éticos que norteiem as relações estabelecidas entre professores, pais e alunos no interior das escolas brasileiras, e é necessário inserir a discussão sobre o tratamento que a escola tem dado às relações raciais no interior desse debate.

Necessitamos de inspirações formativas, de responsabilidade ética, de encantamento para que os acontecimentos, "as coisas", sejam sentido de mudanças, que imprimam perspectivas de outras construções epistemológicas, novas políticas econômicas, sociais e culturais, que despertam e impulsionam o agir. É esse encantamento que nos qualifica no mundo, que embeleza o pensar/fazer implicado, no produzir conhecimento com sentidos, todos eles, pois "se ao aprender envolvemos sensibilidades, sabemos também que as sensibilidades aprendem. Se o ato de cuidar é acima de tudo um gesto ético-político, aí está imbricado também um gesto sensivel que envolve o ato de aprender ${ }^{10 "}$ (MACEDO, 2013, p. 99).

$\mathrm{O}$ ato de contar histórias está adaptado ao lugar, ao tempo. Contamos histórias com os dedos (escrevendo), com o giz, o pincel, a dança, o fazer diferente, pois o aprender/ensinar trança conhecimentos, une, separa, faz diferente. Produzimos não apenas com palavras escritas, faladas, mas também com os movimentos dos nossos corpos, pois este, não está separado da ação do conhecer/aprender/ensinar e tudo isto constitui o criar / produzir filosofia africana.

Pesquisar sobre a Filosofia Africana implica numa necessidade de ressignificar o educar, assim como o currículo, este que se apresenta como a expressão do que constitui o conhecimento, é linguagem, texto, representação e assim produtor e "circulador" de signos, $e$ - por ser produtor de identidade e alteridade - aproximase da Filosofia Africana, que análoga à origem é alimentada pela literatura,

\footnotetext{
${ }^{10}$ Grifo do autor.
} 
antropologia, história, assim como pelos provérbios e mitos, dentre outros. Tais elementos proporcionam conhecimentos e pensamentos filosóficos fundamentais, onde a oralidade traz um farto conhecimento ancestral (MACHADO, 2012).

Continuamente é indispensável chamar a atenção para a importância, nas culturas africanas e afrodescendentes, da oralidade. As histórias contadas relembram e, além de registrarem o passado, transmitem conhecimentos, são histórias constituídas de "moral" e que primam pela ética. As palavras, os gestos, as cerimônias, os ritos, todos os comportamentos envolvidos produzem filosofia, a transmitem, educam.

Atualmente a oralidade continua com grande importância, no entanto divide seu espaço com a escrita, com formas de conhecimentos de outras culturas, é o entrelaçamento, a multiculturalidade co-existindo, pois,

longe de serem opostas, a fala e a escrita são entrelaçadas, tecidos diferentes do mesmo cachecol. Palavra, linguagem. Cada uma tem, sim, detalhes próprios, mas são como um casal de amantes que se relacionam, dando soltura para suas personalidades. (...) Talvez, entre as diferenças surjam rojões e sussurros que demonstrem o quanto cada universo, do papel ou da escuta, tem de seu, de só seu. E essas diferenças estão no chão da caminhada, propiciando força, oferecendo base para os calcanhares das artes e dos ofícios verbais, dando assentamento ou até cansando o corpo nas expressões desaprumadas (ROSA, 2009, p. 90).

Desse modo, questiono: Por que não pensar em Ananse como um(a) bailarino(a) que junta corpos, espalha conhecimento? Os corpos ainda que diferentes são sempre passíveis de dançar e encantar, ainda que se dance "sozinho/a", nunca está sozinho/a, pois não existimos sozinhos, "somos pedacinhos de alteridade" (OLIVEIRA, 2007), só existimos porquê existe o/a outro/a, já dizia a filosofia Ubuntu, nessa cultura "temos a existência definida pela existência de outras existências. Eu, nós existimos porque você e outros existem" (CUNHA JR., 2010, p. 81). Assis, as expressões ainda que "desaprumadas" entrelaçam nossos corpos na arte do viver, expressões emaranhadas em espertezas e artimanhas para a sobrevivência, para o existir. 


\section{2 - Ananse no currículo: esperteza e artimanhas para um sentido outro}

Compreendendo a filosofia africana como possível em nosso país por sermos afro-brasileiros, africanos nascidos cá e termos na ancestralidade o conceito fundante do nosso pensamento, ancestralidade que evocada desde os antepassados nos conta a história da nossa origem, a glória dos nossos antepassados, transmitindo os conhecimentos acumulados ao longo dos séculos, atualizando-os continuamente, delineando nosso modo de fazer / pensar / criar. Pois, assim como Ananse, aqueles que aqui foram escravizados tiveram que empregar suas espertezas, suas criatividades e agir com artimanhas para sobreviverem, além da sabedoria incrivel em realizar a difícil e complexa ação do sincretismo de suas culturas com a cultura do colonizador, do país para onde foram enviados, sabedoria como modo de continuarem cultuando sua religião (principalmente), suas comidas, danças, etc, pois, desde que aqui chegaram, os africanos trouxeram consigo o seu modo de interpretar a realidade, seu modo de vida, herança esta que exerceu e continua exercendo um papel preponderante na construção da brasilidade que tanto tem de africanidade, esta que, em sua pluralidade:

re-desenham e re-definem a identidade nacional e, com isso, o projeto político, econômico e social brasileiro. Ainda que o discurso político e acadêmico tenha excluído, durante séculos, a experiência africana no Brasil, sua influência não deixou de exercer papel fundamental na construção do país (OLIVEIRA, 2006, p. 18).

A implementação da Lei 10.639/2003 faz-se na ação cotidiana, por meio dos atos de currículos, em que estes aparecem como o "lugar da construção das hegemonias e re-existências, por processos híbridos, por contextualizações, descontextualizações e recontextualizações" (MACEDO, 2012, p. 73), onde "conteúdo e forma, instituído e instituinte são concebidos, refletidos e vividos cotidianamente" (Idem). Os acontecimentos cotidianos, aliados à escuta, são fundamentais para a mudança das estruturas vigentes, onde a educação escolar 
ultrapassa as paredes das escolas, onde os atos de currículo fundam a possibilidade de compreensão do currículo como processo de alteração incessante, implicando em políticas de sentido, políticas de conhecimento, luta por significados, necessitando aí, por consequência, uma revisão da política sobre a natureza das alterações produzidas nas experiências formativas.

É assim que a filosofia africana permeada pela ancestralidade traz subsídios para o ensino de história e cultura africana e afro-brasileira, constituindo-se num modo de pensar e agir, onde o indivíduo é a preocupação fundamental e assim a inclusão e a alteridade fazem-se preponderante, pois "o diagrama da filosofia africana é construído no plano horizontal da solidariedade" (OLIVEIRA, 2006, p.160). Esse plano faz-se de modo circular, onde todos estão incluídos, e assim é o símbolo de Ananse, um círculo que imprime sua sabedoria, esperteza, criatividade para encarar a complexidade da vida, dando um sentido outro, um sentido solidário para o existir, uma ética para o "bem-viver"11.

\section{3 - Filosofia Africana: ressignificando a educação e o currículo.}

A Filosofia africana elaborada desde os princípios e valores que regem a vida dos africanos e afrodescendentes, dentro da sua imensa diversidade, abre-se para as possibilidades, sai de uma totalidade para pensar / refletir / agir desde a alteridade, desde o encantamento, enxerga a diversidade em vez da identidade, deseja a diversidade existente na unidade, é atitude e não uma metafísica, é corpo inteiro e não apenas razão, posto que "em formação é preciso entender que a emoção coloca o sujeito em movimento e o impulsiona para a ação" (MACEDO, 2010, p. 129), é uma filosofia do movimento. Prima por uma ética de inclusão, é ciência da sensibilidade, é estética, pensa epistemologias para a vida e mundos melhores, busca conhecimentos propositivos de uma mudança consistente, trabalha com epistemologias para a práxis. Uma constelação filosófica que

\footnotetext{
${ }^{11}$ Bem-Viver é um conceito filosófico oriundo da Filosofia da Libertação na década de 90 . Segundo Euclides Mance (Revista Camponesa da AACCRN, 2013) "quando se trata da libertação e não apenas da liberdade, afirma-se que é necessário assegurar a todas as pessoas as condições econômicas, ecológicas, politicas, educativas, informativas e éticas para realizar as suas liberdades, tanto publicas quanto privadas". O autor concebe que expandir as liberdades implica na realização do bem-viver de cada um e de todos, é então, "uma categoria filosófica muito importante para criticar toda forma de dominação e toda forma de libertação" (Idem).
} 
proporciona a possibilidade de um currículo inclusivo, diverso e acolhedor para o ensino de história e cultura africana e afro-brasileira e de outras culturas.

Filosofia é produção, é ressignificação de conceitos, mudança de paradigmas, onde o contexto, a cultura local e o tempo histórico são fundamentais. Onde a voz de todos é valorizada à medida que se escuta e se pensa o e com o Outro. É o movimento da alteridade. É movimento do encantamento. O filosofar, o educar e o currículo não se conjugam pura e simplesmente na racionalização, mas no pensar / sentir de corpo inteiro, com cheiro, lágrimas, suor... é rosa com pétalas e espinhos! Filosofia / educação / currículo constroem mundos, pois viver é construir mundos! Pois, "aprender num cenário curricular (...) é aprender em meio a uma cultura densa, estruturante e opcionada..." (Idem, p. 117).

A filosofia africana contemporânea traz a cultura como eixo central da sua constituição, é fruto da experiência, é feita não apenas por filósofos africanos, mas também por aqueles que estão implicados em direcionar sua atenção aos problemas dos africanos, sejam os nascidos em África ou aqueles que são frutos das diásporas, que têm a África nascida em si. Intenta-se resolver os problemas desde suas concepções de vida, suas culturas, crendices, mitos, poesias, etc...

Essa filosofia que reflete o homem africano desde uma negação contínua da escravidão e colonização, e afirmando positivamente a si e a sua cultura, nasceu com o nome de "etnofilosofia", consistindo no intento de elaborar sistematicamente uma filosofia através do uso das categorias etnológicas tradicionais, marcando um ponto do início da filosofia africana, proporcionando o desenvolvimento do pensar africano consciente de si, da sua diversidade cultural.

Diversas pesquisas assinalam que são os próprios estudos sobre a origem da filosofia que provam sua origem na África Negra. No entanto, o tema "filosofia africana" tem sido recente nas investigações dos estudiosos africanos, há pouco mais de cinquenta anos começou-se a realizar essas reflexões, tendo-a como tema acadêmico de investigação, debate e aprendizagens, ou seja, "o início do debate filosófico africano moderno equipara-se para muitos à sua entrada como disciplina acadêmica nas universidades em África” (SEILER, 2009, p. 22). Tshiamalenga (apud NKOGO, 2006, p. 42) considera que: 
La filosofia africana contemporânea estaria, a su vez, constituída por los esquemas hechos por los filósofos africanos y africanistas, inspirados en métodos científicos, ya sea para 'restituir' un pensamiento africano tradicional original, ordenado por la fidelidad a los valores ancestrales y por los imperativos de la liberación, ya sea para criticar, de forma constructiva, las investigaciones africanas em curso.

Objetivando responder aos questionamentos sobre sua existência, a universalidade (filosofia) e a particularidade (africana), demarcamos algumas correntes $^{12}$ que podem ser consideradas núcleos da Filosofia Africana Contemporânea. São as seguintes: Etnofilosofia, Sagacidade Filosófica (Filosofia da Sagacidade ou Filosofia dos Sábios), Filosofia Nacionalista-Ideológica ou Filosofia Política, Filosofia Profissional ou Acadêmica ${ }^{13}$. Em classificações mais recentes incluiu-se filosofia literária / artística ou poética e Hermenêutica ${ }^{14}$, que seriam correntes, na minha compreensão, culturalistas ${ }^{15}$. Também é importante evidenciar que dentro dessas correntes particulares há outras correntes com suas singularidades. Daí a filosofia africana desenvolve-se continuamente.

Assim, Ananse tece os fios da sua teia, pensando na diversidade, no movimento que um currículo outro pode nos proporcionar, currículo este que

12 Sabemos do quão delicado é estudar as correntes que constituem o pensamento africano, no entanto, a nível metodológico estaremos apontando essas correntes como delineadoras do nosso trabalho. Oruka (1994, p. 7) diz que "y la clasificación de las diferentes tendencias debiera verse como un medio para nosotros, en Africa, de aislar la filosofía en el sentido estricto de la filosofía en el sentido amplio y omnícomprensívo". Aqui seguimos a divisão realizada por Oruka (1988. p. 3537). Num artigo que data de 1994, p. 7, ele traz o seguinte: "Las cuatro tendencias" como: 1) textos filosóficos profesionales, i, e., trabajos de académicos y estudiantes formalmente adiestrados en filosofía; 2) teorías ideológicas nacionalistas y 3) estudios etnográficos de las creencias africanas tradicionales etiquetadas como 'filosofia'-i. e., etnofilosofía. La filosofía de los sábios llega a ser una cuarta tendencia en esta ista".

${ }^{13}$ Vide Machado 2012, 2014. Onde há um maior desenvolvimento sobre a filosofia africana e suas correntes.

${ }^{14}$ Classificações mais recentes já incluem a Filosofia Feminista.

${ }^{15}$ Estamos desenvolvendo (a linha de pesquisa ACHEI) um Mapa Conceitual do Pensamento Africano e Latino Americano, atualizando-o dentro do pensamento da filosofia afrobrasileira com o conceito de Ancestralidade. Esse mapa está dividido em Geopolítica, Geocultura e Ancestralidade. No que se refere à Filosofia Africana dividiríamos as correntes da seguinte forma: (Sagacidade Filosófica, Filosofia Política, Filosofia Profissional) e Geocultura (Etnofilosofia, Sagacidade Filosófica, Filosofia Literária/Artística e Hermenêutica), em consequência da grande dificuldade em classificar os autores dentro dessas correntes (sendo que em sua maioria os autores estão em mais de uma corrente), optamos por trabalhar com os três movimentos: Geopolítica, Geocultura e Ancestralidade. 
encontra na diversidade a unidade de uma educação que pensa o outro, que escuta outras vozes, transforma um movimento em outro, olha para a cultura local e não exclui as outras culturas, espalha sabedoria / conhecimento pelo mundo. Onde "As teias do de dentro desenham uma rede com os fios dos de fora" (Oliveira, 2007, p.312). Onde a filosofia africana delineada desde a ancestralidade tece as teias do pensamento afro-brasileiro.

\section{4 - In-Conclusões Formativas}

Concluímos que do artigo $26 \mathrm{~A}$ da LDB, a problemática da formação docente é de suma importância e ela prescinde de uma sensibilização, que é primordial para a implementação de um currículo que contenha elementos silenciados na história de nosso país para que possamos também construir um conjunto de conhecimentos/conteúdos não estereotipados, carregados de preconceitos sobre a história e a cultura africana e afro-brasileira.

A relatora da Lei 10.639, Petronilha Silva ${ }^{16}$ (2012), ao falar sobre como a realidade a partir da referida lei pode ser mudada desde o sistema escolar nos diz que:

A referida determinação da Lei de Diretrizes e Bases da Educação visa, educar a todos os brasileiros e brasileiras para que conheçam, respeitem e valorizem uma das raízes fundadoras de sua cultura e nacionalidade, a africana. O que precisa ser mudada não é a imagem dos negros, mas a imagem negativa que a sociedade criou e fomenta como se fosse própria deles. Uma imagem que muitos brasileiros, que pretendem manter privilégios e direitos para si próprios $e$ seus grupos originários, cultivam, tentando fazer com que todos partilhem do ideal de fazer do Brasil uma nação monocultural, de raiz predominantemente europeia. Os sistemas de ensino $e$ as escolas de diferentes níveis da educação - infantil ao superior - são espaços necessários e competentes para combater o racismo e discriminações, assegurando, conforme consta do Parecer CNE/CP3/2004, "o direito à igualdade de condições de vida e cidadania",

\footnotetext{
${ }^{16}$ Entrevista cedida a Daiane Sousa em 11 de Janeiro de 2012, para o portal da Fundação Cultural Palmares: http://www.palmares.gov.br/2012/01/a-lei-n\%C2\%B0-10-639-sob-a-visao-de-petronilhabeatriz-goncalves-e-silva/
} 
assim como garantindo "igual direito às histórias e culturas que compõem a nação brasileira, além do direito de acesso à diferentes fontes da cultura nacional a todos os brasileiros".

Petronilha Silva segue afirmando que tornar obrigatório o ensino de História e Cultura Afro-brasileira e Africana tem o intuito de "reeducar as relações étnicoraciais a fim de que todos - descendentes de europeus, asiáticos, africanos e povos indígenas - valorizem a identidade, a cultura e a história dos negros que constituem o segmento mais desrespeitado da nossa sociedade" (idem), posto que ao longo dos séculos o racismo criou e propagou diversas estratégias com o objetivo de "manter os negros brasileiros à margem dos direitos devidos a todos os cidadãos, sobretudo os negros que se reconhecem descendentes de africanos, que se negam deixar assimilar por ideias e conhecimentos depreciativos de tudo que vem da sabedoria construída a partir de suas raízes" (ibidem).

Desse modo, para desconstruir essa realidade negativada e positivar nossa história, nossos conhecimentos, nossas culturas, sua diversidade e suas singularidades, o encantamento faz-se imprescindível, pois, é essa relação encantada com um determinado conhecimento que provoca mudanças, que o faz diferenciado e assim provoca transformações garantindo uma educação outra, uma educação antirracista e não apenas acumulação de conhecimentos, é um conhecimento oriundo da reflexão, do sentir e assim, dá sentido.

Ananse deixa isso fulgente, afinal, ele tinha todo o conhecimento do mundo, mas foi uma experiência vivenciada, um encontro que afetou sua sensibilidade e o permitiu notar que ter informações acumuladas não é o suficiente, é preciso nos entrelaçarmos com as experiências vivenciadas e o que elas nos trazem... é preciso dançar com!

A receita não está dada, não há um jeito certo ou errado de tecer a teia, o objetivo, o desejo fundante é o autorizar-se e autorizar o outro a refletir, produzir, construir, descontruir, reconstruir. Assim, a ancestralidade e o encantamento aparecem como inspirações formativas, como compreensão de que a formação está imbricada nesses próprios conceitos, é compreender que a reflexão só pode ser produtora de sentidos quando parte da experiência... 
A compreensão de nós mesmos e do lugar onde celebramos

a ancestralidade renova a vida de velhos e novos.

Vanda Machado

\section{REFERÊNCIAS:}

BÂ, Amadou Hampâté. Amkoullel, o menino fula. São Paulo: Palas Athenas: Casa das Áfricas, 2003.

BRASIL. Ministério da Educação. Secretaria Especial de Políticas de Promoção da Igualdade Racial. Plano Nacional de Implementação das Diretrizes Curriculares Nacionais para Educação das Relaçóes Etnicorraciais e para o Ensino de História e Cultura Afro-Brasileira e Africana. Brasília: MEC, 2009.

Ministério da Educação. Secretaria de Educação Continuada, Alfabetização e Diversidade. Diretrizes Curriculares Nacionais para a Educação das Relações Étnico- Raciais. Brasilia: MEC, 2004.Disponível em: $<$ http://portal.mec.gov.br/cne/>.

BRANDÃO, Carlos Rodrigues. O que é educação. São Paulo: Brasiliense, 2007.(Coleção primeiros passos; 20).

CUNHA JR. Henrique. História e Cultura Africana e os Elementos para uma organização Curricular. Fortaleza, Mimeo, S/d.

A inclusão da história africana no tempo dos parâmetros curriculares nacionais. In: Núcleo de Estudos Interdisciplinares sobre o Negro Brasileiro. São Paulo: USP, 2007. Acesso em 20 de janeiro de 2013, Visitado em: http://cassiuscruz.multiply.com/journal/item/2?\&show interstitial=1\&u=\%2Fjourna 1\%2Fitem

Ntu. Revista Espaço Acadêmico, Nº108, maio, 2010.

FLOR DO NASCIMENTO, Wanderson. Outras vozes no ensino de filosofia: O pensamento africano e afro-brasileiro. Revista Sul-Americana de Filosofia $e$ Educação. Número 18: maio-out/2012, p. 74-89. Acesso em 01 de Junho de 2012.

Pensando a Escola: entre a formação e a liberdade. Revista Sul-Americana de Filosofia e Educação. Número 6/7: maio/2006 - abril/2007, p. 76-100. Acesso em 04 de Setembro de 2012.

FLOR DO NASCIMENTO, Wanderson; BOTELHO, Denise. Colonialidade e Educação: O currículo de filosofia brasileiro entre discursos coloniais. Revista SulAmericana de Filosofia e Educação. Número 14: maio-out/2010, p. 66-89.

FOÉ, Nkolo. A questão do negro no mundo moderno. Sankofa: Revista de História da África e de Estudos da Diáspora Africana. Ano IV, N8, Dezembro de 2011.

GOMES, Nilma Lino. Educação e relações raciais: refletindo sobre algumas estratégias de atuação. In: MUNANGA, Kabengele (org.) Superando o racismo na escola.Brasília: MEC.2000.

MAZRUI, Ali A.; AJAYI, J.F. Tendências da Filosofia e da Ciência na África. In: História Geral da África, VIII: África desde 1935. Editado por Ali A. Mazrui. 2.ed.rev. - Brasilia: Unesco, 2010.

MACEDO, Roberto Sidnei. Atos de Currículo e Autonomia Pedagógica: o socioconstrucionismo curricular em perspectiva. Petrópolis, RJ: Vozes, 2013. 
A etnopesquisa implicada: pertencimento, criação de saberes $e$

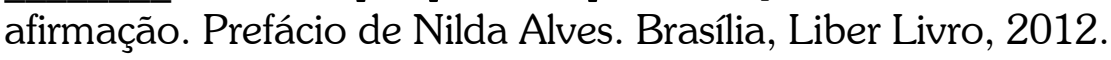

Atos de Currículo e Formação: o príncipe provocado. Revista Teias v. 13, n.27, 67-74. 2012. Currículos: Problematização em práticas e políticas. Disponível em: http://www.periodicos.proped.pro.br/index.php?journal =revistateias\&page $=$ issue \& op=view\&path[]=56\&path[]=showToc. Visitado em 06 de maio de 2012a.

. Compreender/mediar a formação: o fundante da educação. Prefácio de Marie-Christine Josso; apresentação de Jacqueline Monbaron-Houriet. Brasília: Liber Livro Editora, 2010.

MACEDO, R. . O rigor fecundo: a etnopesquisa crítica como analítica sensível $e$ rigorosa do processo educativo. Revista entreideias: educação, cultura e sociedade, América do Norte, 5, mai. 2007a. Disponível em: http://www.portalseer.ufba.br/index.php/entreideias/article/view/2946/2110. Acesso em: 15 Mar. 2012.

MACHADO, Adilbênia Freire. Filosofia Africana e Currículo: Aproximações. Revista Sul-Americana de Filosofia e Educação, Brasília, Vol.0, N.18, maio de 2012.

em:

http://seer.bce.unb.br/index.php/resafe/article/view/7027/5552

. Linguagem e Identidade Africana e Afrobrasileira. Fólio - Revista de

Letras, Vitória da Conquista, Vol.3, N.2, 2012b. Disponível em: http://periodicos.uesb.br/index.php/folio/article/viewFile/619/772

MANCE, Euclides André. Camponesa da AACCRN (Associação de Apoio às Comunidades do Campo do Rio Grande do Norte). Entrevista do Professor Euclides Mance, Março de 2013. Disponível em http://www.fbes.org.br/index2.php?option $=$ com_docman\&task $=$ doc_view\&gid $=1$ 787\&Itemid $=18$. Visitada em Fevereiro de 2014.

MIRANDA, Eraldo. O dia em que Ananse espalhou a sabedoria pelo mundo. $1^{\mathrm{a}}$ Edição, São Paulo: Elementar, 2008.

MUNANGA, Kabengele. Apresentação.In: MUNANGA, Kabengele ( org.) Superando o racismo na escola. Brasília: MEC.2000.

NKOGO, Eugenio. Síntesis Sistemática de La Filosofía Africana. Barcelona, 2006. OLIVEIRA, David Eduardo de. Filosofia da ancestralidade como filosofia africana: Educação e cultura afro-brasileira. Revista Sul-Americana de Filosofia e Educação. Número 18: maio-out/2012, p.28-47. Disponível em: http://seer.bce.unb.br/index.php/resafe/article/view/7029. Acesso em 1 de Junho de 2012.

Filosofia da ancestralidade: corpo e mito na filosofia da educação brasileira. Curitiba: Editora Gráfica Popular, 2007.

Cosmovisão africana no Brasil: elementos para uma filosofia afrodescendente. Curitiba: Editora Gráfica Popular, 2006.

RIBEIRO, Ronilda Iyakemi. De Boca Perfumada a Ouvidos Dóceis e Limpos: Ancestralidades Africanas, Tradição Oral e Cultura Brasileira. Itineráios, Araraquara, No 13, 1998.

ROSA, Allan Santos da. Imaginário, Corpo e Caneta: Matriz Afro-Brasileira em Educação de Jovens e Adulto. São Paulo: FEUSP, 2009 (Dissertação de Mestrado). Disponível em: 
http://www.edicoestoro.net/attachments/059 Imagin\%C3\%A1rio,\%20Como\%20e\%20Caneta.pdf. Visitado em 02 de Julho de 2011.

SILVA, Tomaz Tadeu da. O currículo como fetiche: a poética e a política do texto curricular. Belo Horizonte: Autêntica Editora, 2010.

SILVA, Petronilha (Relatora). Diretrizes Curriculares Nacionais para a Educação das Relações Étnico-Raciais. Brasília - DF: Conselho Nacional de Educação, 2004. SOMÉ, Sobonfu. O Espírito da Intimidade: ensinamentos ancestrais africanos sobre relacionamentos. SP: Odysseus Editora, 2003. 